\title{
O corpo e violência na psicanálise
}

\author{
Ondina Machado \\ Psicanalista, membro da EBP-AMP, doutora em Psicanálise UFRJ e \\ coordenadora de Pesquisa "Clínica e política do ato" ICP-RJ. \\ ondinamrm@gmail.com
}

Resumo: Explorando a concepção do corpo como imagem e como gozo, o texto se propõe a tratar da violência que incide no corpo sob o ponto de vista da psicanálise. Aborda a diferença entre o conceito freudiano de agressividade e a violência que conhecemos nos dias atuais e faz algumas considerações sobre a violência contra mulheres, situando-a no campo do racismo.

Palavras-chave: corpo, violência, agressividade, violência contra a mulher.

Abstract: Exploring the conception of the body as an image and as joy, the text proposes to deal with the violence that affects the body from the point of view of psychoanalysis. It addresses the difference between the Freudian concept of aggression and violence that we know today and makes some considerations about violence against women, placing it in the field of racism.

Key-words: body, violence, aggressiviness, violence against women.

\section{Violência e psicanálise}

Violência é um substantivo que designa a 'qualidade de violento'. É derivado da raiz latina vis (força) que dá origem ao adjetivo violento e ao verbo violare, que tanto pode ser traduzido por violar como por coagir, profanar e transgredir. Etimologicamente violência é uma ação de força usada contra outra pessoa. ${ }^{1}$

Não há uma definição sociológica, antropológica ou criminal para o que é violência. De modo geral, na forma simples, a palavra violência é usada para falar de um dano físico; quando o dano não é físico, usam-se formas compostas: violência moral, violência psicológica, violência de gênero e assim por diante.

1 MACHADO, O.M.R.; DEREZENSKY, E. A violência: sintoma social da época. Belo Horizonte: Scriptum/ EBP, 2013, p. 129. 
Pensando nessa extensão atual do termo, podemos classificar como violenta uma diversidade de ações, palavras ou mesmo simples gestos que abarcariam um mundo de coisas. Para complicar, teríamos também que contar com o testemunho daquele que teria sofrido a violência, pois não há gesto, ato ou palavra que por si só seja violento. Se levarmos em conta as consequências como critério para classificar o que é ou não violento, teríamos como limite a morte. Mesmo ela, nas mãos de um bom advogado, revestida de motivos ideológicos ou nos países que admitem a eutanásia, pode ganhar outra conotação. Cada estrutura clínica tem seu ponto de vulnerabilidade e, dentro dela, cada sujeito, por sua singular trama fantasmática, pode ser tocado, mesmo acidentalmente, em algo cuja falta de representação torna-o insuportável desencadeando reações violentas.

Falar sobre violência em psicanálise tem mais um fator complicador: em nosso campo não há o conceito de violência. A agressividade foi alvo da investigação de Freud, esta sim faz parte de nosso estofo conceitual e nos serve para pensar a violência, inclusive ensaiar suas diferenças. Muitas vezes ele usou esses termos como sinônimos, mas devemos ponderar que Freud viveu entre as duas primeiras guerras mundiais, momento no qual a agressividade humana, mesmo que não desconhecida, surpreendeu pela proporção que atingiu.

Quando falamos de violência nos dias atuais parece que é de outra coisa que tratamos. Não reconhecemos nela a agressividade própria ao homem acuado por um inimigo, há alguma coisa além do 'ou eu ou ele'. Não se trata de eliminar um inimigo, de roubar um bem, se aproxima mais de uma necessidade imperiosa daquele que a pratica do que de uma reação a algum ataque sofrido. Em geral não há relação causal entre o ato praticado e o motivo alegado, do mesmo modo se observa uma desproporcionalidade na agressão. A violência é um fenômeno do século XXI que se iniciou com o ataque às Torres Gêmeas, prosseguiu com assassinatos de massa e diversos atentados de cunho ideológico.

Se compreendemos que agressividade e violência são fenômenos diversos, podemos nos perguntar a que concepção de corpo eles correspondem. Preliminarmente podemos dizer que a agressividade se dirige ao outro semelhante, aquele da imagem especular que sou eu, mas que no espelho se configura como um não-eu. A violência, porém, se dirige ao Outro, lugar de alteridade que, ao mesmo tempo que é Outro, é também algo em mim que não pode ser percebido como meu e por isso rejeito no Outro.

\section{Agressividade}

A agressividade é um ao jogo de projeções produzidas no espelho que constituem o eu, o outro e o objeto, elementos que compõem a dialética das identificações. O investimento libidinal na imagem projetada produz o corpo imagem, ele é concebido como uma totalidade e tem o poder de capturar e alienar o eu. Freud chamou isso de narcisismo, ou seja, o resultado do encantamento do eu com sua imagem. A identificação do eu com seu corpo faz com que pensemos que somos nosso corpo, portanto, que há uma analogia entre eu e corpo. Veremos a importância disso quando verificarmos que essa coincidência não existe, justamente porque o eu não recobre o sujeito ou, como diz Miquel Bassols, "teu eu não é teu". ${ }^{2}$ A relação idílica que aparentemente se arma não resiste a incidência dos significantes sobre o corpo, eles fragmentam a boa forma, produzem desconforto e conflitos com tudo que se configura como não-eu.

2 BASSOLS, M. Tu yo no es tuyo. Buenos Aires: Tres Haches, 2010. 
A relação idílica que aparentemente se arma não resiste a incidência dos significantes sobre o corpo, eles fragmentam a boa forma, produzem desconforto e conflitos com tudo que se configura como não-eu. $\mathrm{O}$ desacordo entre a unidade imaginária e a incidência do significante incita, como diz Lacan, uma "concorrência agressiva". ${ }^{3} \mathrm{O}$ transitivismo infantil, que atribui à pedra a causa da topada, demonstra a precoce apreensão do semelhante como ameaçador e a vocação paranoica do eu.

Foi no campo do eu, da alienação do sujeito à imagem de seu corpo e da ameaça à integridade imaginária, que Freud tratou a animosidade entre os homens, seja ela manifesta na guerra, no parricídio, no ciúme ou na vingança. Podemos localizar em seus textos duas versões para a agressividade: uma egóica e outra superegóica. Na primeira, ele mostra o quanto a agressividade humana é diferente da animal, contrariando assim as teses naturalistas que tentam justificar a hostilidade por um suposto instinto de preservação da espécie. ${ }^{4}$ Fica claro que, no caso dos humanos, a agressividade tem a ver com os afetos envolvidos nas relações, não porque sejam bons ou maus, positivos ou negativos, amorosos ou hostis, mas que toda relação humana é potencialmente agressiva. Este potencial não chegou a dizimar a humanidade devido a uma característica dos afetos - eles são passíveis de serem recalcados. O recalcamento, então, mantém a agressividade no campo da fantasia, como um sentimento íntimo, tão íntimo que, na clínica, ele pode aparecer sob a forma do altruísmo ou da culpa, como formações reativas à própria agressividade.

Na concepção superegóica da agressividade podemos destacar tanto as considerações que aparecem em "Além do Princípio do Prazer", de 1920, quanto as presentes em "O ego e o id", de 1923. No primeiro Freud se depara com a tendência do homem à destruição e no segundo, ele vai mostrar que a agressividade aparece em resposta às exigências morais do supereu. Em ambas podemos perceber que há uma vinculação da agressividade às pulsões do eu e de autoconservação, portanto, se enquadram na lógica da proteção. Porém, identifica-se também a incitação do supereu, relativa à pulsão de morte, que contraria essa lógica e leva o sujeito na direção do que Lacan chamará de gozo. É esse último aspecto que desenvolveremos a seguir e que nos parece estar mais ligado ao corpo da violência.

\section{Violência}

A maldade humana, para Freud, seria um nome genérico para a natureza agressiva que tanto pode se dirigir ao outro como a si mesmo. Crimes e suicídios são praticados tendo por base a estrutura paranoica do eu, alguns deles servindo de solução para delírios e alucinações psicóticas ou como resposta neurótica à fantasia.

Coisa bem distinta, me parece, é a violência. Das poucas referências a ela em Lacan, uma orientou minha pesquisa ${ }^{5}$ e foi o núcleo de um relatório apresentado nas Conversações do VI ENAPOL.6 Trata-se de um trecho do Seminário 5 no qual Lacan critica a análise das resistências, prática corriqueira entre os pós-freudianos.

3 LACAN, J. "A agressividade em psicanálise". In: Escritos. Rio de Janeiro: Jorge Zahar Editor, 1998, p. 117.

4 C.f. FREUD, S. "Totem e Tabu" (1913) e "O mal-estar na civilização" (1930). Obras Completas.

5 O Grupo de trabalho sobre a violência para o VI Enapol foi composto por: Ondina Machado (coord.), Marcus André Vieira (êxtimo), Ângela Gentile, Flávia Brasil, Gláucia Barbosa, Gustavo Fonseca, Heloisa Shimabukuro, Lenita Bentes, Leonardo Miranda, Maria Lúcia Celestino, Mariana Mollica.

6 MACHADO, O.. "A violência urbana nos dias atuais". Disponível em:

http:/ / www.enapol.com/pt/template.php?file=Las-Conversaciones-del-ENAPOL/La-violencia-y-el-nuevoorden/Ondina-Machado.html. Acesso em: 20 abril 2019. 
Ele diz que a interpretação da resistência, além de não acabar com ela, faz com que o analista colabore com o sintoma. Não podemos esquecer que a resistência, nessa época, era entendida como um ataque ao tratamento e, por isso, ele faz questão de marcar a ambuiguidade com que o termo agressividade era tratado. Esclarece que "a agressividade provocada na relação imaginária com o pequeno outro não pode confundir-se com a totalidade do poder agressivo". ' A violência, segundo ele, "é o que há de essencial na agressão" e que ela distingue-se da fala: "o que pode produzir-se numa relação inter-humana são a violência ou a fala." Tendo como princípio que o recalque somente opera sobre uma articulação significante, Lacan vai questionar se a violência pode ser recalcada, tal como é a agressividade. Segundo ele, a agressividade é interpretável porque o assassinato do semelhante, latente na relação imaginária, foi recalcado.

Nesta citação temos duas importantes indicações para pensar a violência, ambas ligadas ao significante: na primeira é possível ver que sobre ela não recai a barra do recalque e, na segunda, que entre violência e fala há uma incompatibilidade. ${ }^{8}$

Nesta citação temos duas importantes indicações para pensar a violência, ambas ligadas ao significante: na primeira é possível ver que sobre ela não recai a barra do recalque e, na segunda, que entre violência e fala há uma incompatibilidade.

O recalque só pode incidir sobre articulações significantes, ou, para Freud, sobre as representações. São elas que, estando fora do campo da consciência, a ele retornam através das formações criadas pelo inconsciente a partir de restos dessas representações. Nesse sentido, o recalque e as formações construídas com o que dele escapam são produtos que visam a significação. A violência, no entanto, não é feita da mesma matéria. Pensar que se há violência não há fala parece bem razoável, pois o ato violento se antecipa a qualquer enunciado. Mas seria o inverso verdadeiro? Podemos dizer que quando há fala não há violência? A resposta é não. Freud foi enfático ao afirmar que pessoas cultas e povos civilizados não são garantia contra violência.

Não é difícil entender porque o ato violento é incompatível com a fala: toda fala implica uma demanda ao Outro, enquanto o ato é fruto de uma certeza sem dialética, sem Outro. É por isso que Lacan pode afirmar que "nos confins onde a palavra se demite começa o domínio da violência", ' ou seja, o que não é recoberto pela articulação significante pode aparecer como ato.

Tanto para Freud como para Lacan a pulsão age na surdina fazendo um limite à fala; ela é muda, acéfala, constante, sempre se satisfazendo.

Freud deixou como pista a pulsão de morte e Lacan fez dela a pulsão, nem de vida nem de morte, simplesmente pulsão. Miller, por sua vez, enfatiza que a pulsão de morte, tal como Freud a descreve, é na verdade pulsão do supereu ${ }^{10}$ por identificar na exigência do supereu o caráter necessário próprio à pulsão.

Essa passagem orientou um estudo dos crimes que não se inscrevem nem no circuito imaginário, chamados por Lacan de crimes do eu, nem no circuito simbólico, os crimes de autopunição ou crimes do supereu.

7 LACAN, J. O Seminário, livro 5: as formações do inconsciente. Rio de Janeiro: Jorge Zahar Editor, 1999, p. 471.

8 Idem.

9 LACAN, J. "Introdução ao comentário de Jean Hippolite sobre a "Verneinung" de Freud". In: Escritos. Rio de Janeiro: Jorge Zahar Editor, 1998. p. 376.

10 MILLER, J.-A. "Biologia Lacaniana". Opção Lacaniana, São Paulo, n. 41, dezembro de 2004, p. 22.

EntreRios - Revista do PPGANT -UFPI • ano 1, n. 2. 
Em 1950, ${ }^{11}$ Lacan defende que o crime tem uma causa simbólica e por isso afirma que "a psicanálise ao irrealizar o crime, não desumaniza o criminoso" ${ }^{12}$ Ao dar-lhe uma causa subjetiva humaniza o criminoso, em contraposição a uma tendência da época que identificava no criminoso traços de animalidade ou primitivismo.

Esta causa fica mais evidente nos crimes de utilidade; já nos crimes de gozo a contingência simbólica fica apagada em relação à busca imediata da satisfação pulsional. São estes os que mais intrigam a sociedade. Busca-se sempre uma utilidade no crime, quando isso não é possível tentase desumanizar o criminoso.

Lacan considerou também que o crime tem um "móvel social fundamental". ${ }^{13}$ Ao tratar dos crimes do supereu e ligar essa instância "às condições sociais do edipianismo" diz que "as tensões criminosas incluídas na situação familiar só se tornam patogênicas nas sociedades onde essa própria situação se desintegra" ${ }^{14}$ A tese da desintegração da família está presente no texto "Os complexos familiares", no qual reconhecia que a cultura estava se dirigindo à desordem simbólica e que suas consequências repercutiam na formação do supereu. ${ }^{15}$ De instância transmissora de valores, portanto reguladora do gozo, torna-se incitadora ao gozo, o que nos faz considerar que nos crimes de gozo o supereu se apresenta na vertente imperativa. Nos crimes de punição evidencia-se uma articulação com a fantasia, enquanto nos crimes de gozo esta seria ultrapassada.

No plano subjetivo, o ato criminoso denuncia a ineficácia do recalque em passar o gozo para o inconsciente. No plano da cultura, o declínio do simbólico tem como consequência a perda de potência dos semblantes como tratamento ao real do gozo, ficando este dependente das soluções singulares a cada sujeito.

Como paradigma para a violência adoto o que Lacan chamou de crime do isso, ${ }^{16}$ rebatizado por Miller como crime de gozo. Para este autor, existem os crimes de utilidade, que de certa forma recobrem os crimes do eu e os de punição, nos quais a causa está fora dele, seja roubo, castigo, vingança. Existem também os crimes de gozo nos quais o objetivo é o próprio crime. ${ }^{17} \mathrm{E}^{\prime}$ por romper com a lógica da utilidade que o crime de gozo choca e faz crer que não há nele nenhuma causa implicada.

\section{Corpo gozo}

Os crimes de utilidade, ou do eu, e os crimes de gozo demonstram duas concepções de corpo: uma mais ligada às relações imaginárias e sustentada pela unidade corporal e a outra marcada pela satisfação pulsional. Miller, para tratar do corpo como vivo, precisou distinguir dois corpos: o corpo-ego e o corpo-gozo.Há um só organismo que suporta "dois corpos distintos, dois corpos superpostos", ${ }^{18}$ sendo que um sabe o que é preciso para sobreviver e o outro recusa esse saber e suas consequências.

11 LACAN, J. "Introdução teórica às funções da psicanálise em criminologia". In: Escritos. Rio de Janeiro: Zahar Editor, 1998, p.127-151.

12 Ibid., p. 137.

13 Ibid., p.139

14 Ibid., p. 137.

15 LACAN, J. "Os complexos familiares na formação do indivíduo". In: Outros escritos. Rio de Janeiro: Jorge Zahar Editor, 2003, p. 66-67.

16 A classificação apresentada neste parágrafo pode ser encontrada em: LACAN, J. "Introdução teórica às funções da psicanálise em criminologia". Op. Cit.

17 MILLER, J.A. "Préface". In: Biagi-Chaï, F. Le cas Landru. Paris: Imago, 2007, p. 7-17.

18 MILLER, J.-A. "Biologia Lacaniana". Op. cit. p. 49.

EntreRios - Revista do PPGANT -UFPI • ano 1, n. 2. 
As formulações de Lacan sobre o gozo situam sua inutilidade, seu caráter excessivo e sua independência em relação à vontade do sujeito. O gozo se impõe ao sujeito como algo necessário, o que demonstra sua afinidade com a pulsão que visa unicamente a satisfação independe do objeto. Ao mesmo tempo que qualquer objeto serve, não há um que a satisfaça porque nenhum extingue sua força. É isso que faz do gozo uma exigência que despreza o bem-estar do sujeito. É nesse sentido, também, que o crime de gozo não visa a obtenção de um bem, nem qualquer condição externa ao próprio crime. A busca da satisfação pulsional ultrapassa o sujeito, não sofre recalque e não se cifra em um sintoma.

As diferentes concepções do corpo ao longo da civilização ocidental corroboram esta superposição, mas é perceptível que em cada época uma dessas posições prevalece. Na tradição das religiões monoteístas o corpo é uma obra divina, "templo de Deus", intocável e inescrutável. Na Idade Média foi chamado pelo Papa Gregório de "abominável vestimenta da alma"; usado como objeto de sacrifícios e penitências, ${ }^{19}$ estabelece uma ligação entre o gozo e a transgressão. No Renascimento, com os conhecimentos anatômicos, o corpo é investigado pelos cientistas e glorificado pelos artistas. O corpo máquina de Descartes separa mente e corpo que somente se ligam por uma pequena ponte chamada glândula pineal. Como máquina, era um corpo sem vida. A Era Vitoriana impõe restrições severas aos prazeres advindos do corpo, tempos de recalcamento dos desejos. A psicanálise surge nesse contexto repressivo e Freud recebe críticas severas pela importância que dá à sexualidade de um modo geral e, em especial, a sexualidade infantil. No século XX, o corpo é tomado pela via do saber e, assim, é estudado por diversos campos do conhecimento, do biológico ao social, da pedagogia à política.

Na alvorada do século XXI temos o corpo pagão, liberado aos prazeres, virado ao avesso, nano-fragmentado, manipulado geneticamente e, principalmente, inserido no mercado de consumo, está longe da sacralização. Ele hoje é um bem de consumo durável, com prazo de validade extenso, capaz de alta performance, ao qual devem ser oferecidas peças de reposição, recall e possibilitar a customização. É o corpo 'massinha de modelar'. De templo de Deus a templo do gozo, faria corar a rainha Vitória. O modo como tratamos, cuidamos e desafiamos o corpo nos dias atuais não disfarça sua vocação de substância gozante e, talvez por isso, ele se preste mais facilmente ao gozo pelo ato violento como resultado da ruptura do pacto simbólico.

O que me parece decisivo, no que tange à violência, é sua aproximação com a pulsão, quando se verifica seu aspecto necessário, acéfalo e irruptivo. A pulsão, hoje, se manifesta num contexto em que a satisfação alternativa "não eleva o objeto à dignidade de Coisa". ${ }^{20}$ Esta operação equivale a fazer do objeto um semblante, porém, como tudo hoje já tem o estatuto de Coisa, o objeto perde valor e tudo vira semblante, é a chamada semblantização do mundo. Dessa maneira, a operação de fazer com que alguém ou algo tenha um lugar simbólico nas nossas vidas fica prejudicada e a pulsão retoma o circuito buscando satisfação. Mas nada satisfaz porque nada satisfaz totalmente. Esse resto que falta, na verdade é um resto que excede na comparação daquilo que se quer com o que é encontrado.

O sintoma é um meio pelo qual a pulsão se satisfaz, por isso a clínica nos mostra o quanto é difícil abrir mão da parceria que o sujeito faz com seu sintoma. Os rompantes agressivos de um homem ciumento e a constante perda de parceiras poderiam fazê-lo buscar análise, mas isso não se deu enquanto ele imputou ao capricho delas o fracasso das relações. A solução fantasmática levou-o a estabelecer esses rompantes como indicador de que o amor havia acabado.

19 Cf. ELIAS, N. O processo civilizador. Uma história dos costumes. Rio de Janeiro: Jorge Zahar Editor, 1994.

20 LACAN, J. O Seminário, livro 7: a ética da psicanálise. Rio de Janeiro: Jorge Zahar Editor, 1991, p. 140-141.

EntreRios - Revista do PPGANT -UFPI • ano 1, n. 2. 
Desde então, ele troca de parceira a cada ataque, dando a toda relação um caráter passageiro que o desobriga de se questionar sobre isso que o ultrapassa. Seus atos violentos são justificados pela negativa delas em serem aquilo que ele considera "a atitude de uma mulher que ama", deste modo, volta para si, e para a relação, o ponto de real com o qual se depara ao esperar das relações amorosas o objeto que complementaria o seu ser. A suposta traição éo nome que ele dá ao impossível da relação sexual. Diante desse impossível, sua reação é a passagem ao ato violento. Em análise, nas tramas traçadas pela contingência da fala, novos significantes aparecem e possibilitam que ele veja nesses fracassos um gozo insuspeitado.

\section{Violência e corpo feminino}

Uma palavra mais para situar o fenômeno da violência contra mulheres cuja incidência tem sido alarmante. Não está claro se está ou não havendo um aumento dessa incidência, pois sabemos que, mesmo hoje, trata-se de um crime subnotificado. Pensava-se que a falta de uma lei que protegesse mulheres submetidas a atos violentos contribuía para que esses crimes não viessem a público. Hoje, porém, mesmo com a Lei Maria da Penha, ainda nos deparamos com a dificuldade das mulheres em fazer a denúncia. Essa não é uma decisão simples.

Para muitas mulheres que sofrem violência por parte de seus parceiros é difícil denunciar mesmo sabendo que não se trata mais de amor o que os une. Apesar de reconhecerem os riscos que correm, algumas mulheres consideram ser melhor estar "com ele do que sem ele", outras acham que perdas financeiras ou mesmo a ausência da presença do pai no lar fará falta a seus filhos. $^{21}$

Esse é um tipo de violência que demonstra a radicalidade do crime de gozo, o crime cometido porque o agressor não suporta que o Outro goze de maneira diversa da sua. É a mesma lógica do racismo, por isso Miller considera que a violência contra a mulher é uma forma de racismo. $\mathrm{O}$ autor vai além e considera que nesses casos estaríamos em um tipo específico de racismo - o sexismo, ${ }^{22}$ ou seja, ao atacar uma mulher atacasse seu gozo enigmático que por ser diferente torna-se intolerável. Seria por esta diferença que as mulheres entrariam na categoria "minoria" convertendo-se em alvo de segregação.

O racismo tem como base o ódio ao Outro, ou melhor, o ódio ao gozo do Outro. Este Outro pode se localizar em um semelhante, tão próximo que o seu gozo nos incomoda, não só por ser diferente, mas porque se supõe nele um excesso. Porém, se esse excesso está também presente em nós, e sempre está na medida em que todo gozo é excessivo, isso que desconheço em mim meu próprio gozo, eu o rejeito, eu o odeio. Tendo essa perspectiva em vista é possível afirmar que todos, todos nós somos racistas em relação ao ponto em mim que não considero meu por expor o mais íntimo de mim mesmo.

A legítima luta feminista pela igualdade de direitos não se sobrepõe às diferenças entre homens e mulheres, alguns, inclusive, entendem que por estarem mais no espaço público, seja como cidadãs ou profissionais, a rivalidade ficou ainda mais acirrada. Isso pode ser um fato, mas não serve de justificativa na medida em que a violência sempre existiu mesmo no cotidiano da vida das mulheres. Já em 1937, no texto "Análise terminável e interminável", Freud apontava um "repúdio à feminilidade" ${ }^{123}$ que acometia os seres humanos, independente do sexo. Lacan, por sua

21 Maior desenvolvimento desse ponto em: MACHADO, O. "Relaciones violentas y suplencia". Virtualia, Revista Digital da EOL, Buenos Aires, año XVII, n. 35, agosto 2018. Disponível em:

http:/ / www.revistavirtualia.com/articulos/816/lecturas-de-lo-contemporaneo-actualidad-de-la-

clinica/relaciones-violentas-y-suplencia. Acesso em: 19 abril 2019.

22 MILLER, J.-A.. Extimidad. Buenos Aires: Paidós, 2010, p. 55.

23 FREUD, S. "Análise terminável e interminável". Edição Standard Brasileira das Obras Completas, v. 23. Rio de Janeiro: Imago, 1980, p. 268.

EntreRios - Revista do PPGANT -UFPI • ano 1, n. 2. 
vez, expressa a mesma questão no provocativo "Não há A Mulher"124 e quando situa que "a mulher só entra em função na relação sexual enquanto mãe", ${ }^{25}$ portanto desprovida de sexualidade.

Preferimos entender que, em geral, as mulheres têm um modo de estar no mundo que não segue os padrões fálicos ainda predominantes em nossa civilização. A isso chamamos, com Lacan, um modo de gozo não totalmente orientado pelo falo. Se é uma forma de gozo, ela não é exclusiva das mulheres, mas é pouco evidenciada nos homens porque estes vivem a ilusão do órgão, ou a falácia do falo. É essa a diferença que faz com que a violência contra mulheres possa ser entendida como racismo, ou seja, como um crime de ódio.

É inegável o estatuto social do corpo feminino ao longo dos séculos como um corpo público. Desde a propriedade da gestação, que garante a perpetuação da espécie, até mesmo a maneira de se vestir, tudo é alvo da consideração pública. A própria discussão sobre o aborto demonstra o quanto esse corpo entra no discurso político. ${ }^{26}$ Ele faz par com o corpo dos negros, dos indígenas e das crianças, a quem se diz o que é permitido, proibido e esperado.

A violência que presenciamos demonstra o quanto é insuportável lidar com um gozo desconhecido, não só pelos homens, mas também pelas próprias mulheres. Tentar regular esse gozo pela régua fálica, ou como diz Lacan, pela norma macho (norme mâle $)^{27}$ vai na direção oposta à da psicanálise que não trata nem do normal nem do anormal; ela lida com a solução que cada um dá ao seu impossível de suportar.

24 LACAN, J. O Seminário, livro 20: mais, ainda. Rio de Janeiro: Jorge Zahar Editor, 1985, p. 98.

25 Ibid, p. 49.

26 Escola Brasileira de Psicanálise e Observatório A violência e as mulheres na América Latina. "Lei e desejo de filho: sobre a PEC181". Vídeo. Disponível em: https:/ / www.ebp.org.br/canalebp/pec-181/. Acesso em: 19 abril 2019. 27 LACAN, J. "Conférence de Louvain, 1972". Vídeo. Disponível em: https:/ / youtu.be/-HBnLAK4_Cc. Acesso em: 19 abril 2019. 